\title{
EL MODELO DE APOYO A LAS PERSONAS CON CAPACIDADES MODIFICADAS JUDICIALMENTE SEGÚN NACIONES UNIDAS
}

\section{The support model for people with legally modified abilities according to United Nations}

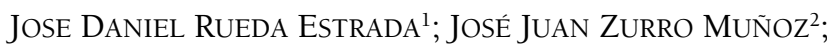 \\ Jose CARLOS FERNÁNDEZ SANCHIDRIÁN ${ }^{3}$
}

\section{Resumen}

Este artículo se basa en una investigación social sobre el sistema de protección jurídica de las personas con algún tipo de discapacidad o en situación de dependencia que se encuentran sometidas a las figuras de tutela o curatela, en aplicación de lo previsto y establecido en el Código Civil Español, en sus artículos 199 y 200, así como en la Ley de Enjuiciamiento Civil.

La investigación se plantea como un estudio comparado entre diferentes países de la Unión Europea para ver su adecuación a lo establecido en el artículo 12 de la Convención de Naciones Unidas sobre derechos de las Personas con Discapacidad (en adelante, CDPD) en los procedimientos de incapacitación. Los resultados se analizan sobre la base de modelos técnico-sociales de intervención, los análisis jurídicos y la experiencia adquirida por las Fundación Tutelares de Castilla y León.

Se proponen y diseñan algunas alternativas y servicios que pueden mejorar la calidad de vida de las personas adultas incapacitadas judicialmente y el tipo de apoyos que se les puede prestar, de acuerdo a lo establecido en la Convención de Naciones Unidas.

Palabras clave: Incapacidad; Discapacidad; Tutela; Apoyo

\begin{abstract}
This article is based on social research into the system of legal protection for persons with disabilities or in a situation of dependence who are subject to the figures of guardianship or conservatorship pursuant to the provisions in the Spanish Civil Code, sections 199 and 200, as well as the Code of Civil Procedure.

The research is presented as a comparative study between different countries of the European Union regarding the adaptation to the provisions of Article 12 of the UN Convention on Rights of Persons with Disabilities (hereinafter CRPD) Incapacitation procedures. The results are analyzed on the basis of technical-social intervention models, legal analysis and the experience of Guardianship Foundations of Castilla y León.

Some alternatives and services are proposed and designed that can improve the quality of life of legally incapacitated persons and the type of support that can be provided to them in accordance with the provisions of the United Nations Convention.
\end{abstract}

Key words: Inability; Disabilities; Guardianship; Support

1. Universidad de Valladolid. Departamento de Sociología y Trabajo Social. Facultad de Educación y Trabajo Social. Valladolid. España. Paseo de Belén, 1. 47011 Valladolid. España. E-mail: jdrueda@ soc.uva.es. Tfno. 983423287

2. Universidad de Valladolid. Departamento de Sociología y Trabajo Social. Facultad de Educación y Trabajo Social. Valladolid. España. Paseo de Belén, 1. 47011 Valladolid. España. E-mail: jjzurro@ soc.uva.es. Tfno: 983184614

3. Universidad de Valladolid. Departamento de Sociología y Trabajo Social. Facultad de Educación y Trabajo Social. Valladolid. España, Paseo de Belén, 1, 47011 Valladolid. España, E-mail: cfsanch@ soc.uva.es, Tfno: 983423454 


\section{Introducción}

La filosofía que emana de la Convención de Naciones Unidas sobre derechos de las Personas con Discapacidad, establece que la capacidad jurídica de cualquier persona no se pierde pese a tener disminuidas capacidades que dificulten el autogobierno. Ello significa que la figura de tutor, como representante y sustituto de una persona con graves limitaciones en su entendimiento y voluntad, deberá ser sustituida por otra que simplemente preste «apoyos» y garantice el ejercicio y realización de todos los derechos de las personas.

La investigación se centra en el papel que deben realizar las entidades privadas y públicas, actualmente entidades tutelares, como entidades prestadoras de apoyos, de acuerdo con la filosofía y articulado de la CDPD. Se circunscribe a Castilla y León, focalizando el análisis en el funcionamiento y la forma de trabajar de tres fundaciones tutelares privadas (Fundación Castellano Leonesa para la tutela de personas mayores -FUNDAMAY-, Fundación Tutelar Castellano Leonesa de Personas con Discapacidad Intelectual o del Desarrollo -FUTUDÍS-, Fundación Tutelar de Personas con Enfermedad Mental -FECLEM-) y una fundación de iniciativa pública (Fundación de Acción Social y Tutela de Castilla y León -FASTCyL-).

Una parte importante del estudio se ha centrado en analizar las legislaciones europeas en materia de incapacitación y tutela para conocer las figuras jurídicas que se están aplicando en materia de protección de derechos de las personas que tienen muy limitadas sus capacidades y requieren una protección especial, judicialmente establecida, de acuerdo a las pruebas aportadas por los profesionales que han de examinar y diagnosticar las capacidades y plantear cuáles deben ser los apoyos que se necesitan para disfrutar en igualdad de condiciones de los derechos sociales y civiles. En este acercamiento se han detectado las figuras «tutelares» que se encargan de prestar los apoyos, asistir a las personas con las capacidades jurídicas modificadas, las obligaciones y responsabilidades que asumen, los ámbitos de actuación y de representación o asistencia que prestan, de acuerdo a las sentencias o indicaciones judiciales.

\section{Objetivos y metodología}

\section{Objetivos}

- Conocer el estado de aplicación, adaptación y/o reforma de las legislaciones europeas en materia de incapacitación y tutela, así como su adecuación a lo previsto en el artículo 12 de la Convención Internacional de los Derechos de las Personas con Discapacidad. 
- Estudiar los procesos de intervención y las formas de prestación de apoyos que las fundaciones tutelares (privadas y pública) de Castilla y León realizan en las tareas de tutela que tienen encomendadas y su adecuación a la mencionada Convención.

- Presentar y analizar un modelo de gestión y organización basado en los criterios de partenariado, gobernanza y cooperación público privada, teniendo en cuenta un planteamiento de actuación centrado en la persona, en la calidad de vida y en la gestión de caso.

- Diseñar un sistema de apoyos a través del voluntariado, como recurso de protección hacia personas que requieran apoyos como consecuencia de su incapacitación y situación de dependencia, con aplicación y uso de las nuevas tecnologías, con el fin de evitar internamientos innecesarios.

- Identificar territorios o países en la Unión Europea con características similares a las de Castilla y León tales como envejecimiento, nivel de renta, dispersión geográfica, para ver la forma de establecer convenios de colaboración en materia de protección jurídica de personas con discapacidad e incapacitadas judicialmente.

\section{Metodología}

El estudio parte de un marco conceptual centrado en el análisis de lo que significa la incapacitación y la tutela de personas adultas y del cambio que introduce en esta materia el artículo 12 de la Convención Internacional de los derechos de las personas con discapacidad, haciendo un recorrido por algunos antecedentes a esta nueva filosofía y enfoque (puntos 3.1 y 3.2). Teniendo en cuenta que el objeto central es hacer un análisis del sistema español sobre incapacidad y tutela y determinar cómo se puede aplicar la filosofía de apoyos que plantea la convención, hemos utilizado diversos procedimientos y metodologías:

1. Estudio y análisis de las Memorias de Fiscalía, con especial referencia a los datos de Castilla y León, a través de los últimos años (20082012), con el fin de ver la incidencia del proceso de incapacitación que se produce en Castilla y León; así mismo se han estudiado diversas sentencias y circulares de los órganos judiciales que marcan la doctrina en materia de tutela e incapacidad para ver si al margen de la reforma del Código Civil en esta materia, las sentencias y doctrina se ajustan a lo establecido en la mencionada Convención. 
2. Estudio de las memorias de actividad de tres fundaciones tutelares privadas de Castilla y León, focalizando el análisis en el funcionamiento y la forma de trabajar (Fundación Castellano Leonesa para la tutela de personas mayores -FUNDAMAY-, Fundación Tutelar Castellano Leonesa de Personas con Discapacidad Intelectual o del Desarrollo -FUTUDÍS-, Fundación Tutelar de Personas con Enfermedad Mental -FECLEM-) y una fundación de iniciativa pública (Fundación de Acción Social y Tutela de Castilla y León -FASTCyL-). A partir de estas memorias y de un cuestionario-ficha hemos podido conocer los procesos y programas de trabajo, así como la cartera y catálogo de servicios de estas fundaciones tutelares.

3. Entrevistas a miembros de los Patronatos y directores-gerentes de las Fundaciones tutelares, para conocer qué se viene haciendo para adaptar los sistemas de tutela a la provisión de apoyos que plantea la Convención. Se han realizado cuatro entrevistas a Gerentes y tres entrevistas a Patronos.

4. Análisis de las legislaciones en materia de tutela e incapacidad y de las directivas o recomendaciones de la Unión Europea y de Naciones Unidas. Para ello se enviaron cartas a las embajadas de los diferentes países de la Unión Europea, para que facilitaran información sobre sus legislaciones y los cambios que se vienen dado en la adaptación de las mismas de acuerdo con lo establecido en la Convención de Naciones Unidas. El objeto de este estudio es el de conocer los sistemas de tutela, las principales figuras y la legislación aplicada y su adecuación a la Convención de Naciones Unidas. Se enviaron cartas a los veintiocho países de la Unión Europea, de los que contestaron Alemania, Bélgica, Bulgaria, Dinamarca, Eslovenia, Estonia, Hungría, Italia, Países Bajos, Polonia, Portugal, Reino Unido y República Checa. Además de esta información se hizo un análisis de la legislación de los Códigos Civiles en materia de tutela e incapacitación de todos los países.

Este material y las herramientas elaboradas permitieron hacer el estudio comparado en materia de tutela y conocer los cambios o procesos de adaptación que se han o se están produciendo.

La fundamentación teórica de la investigación se circunscribe básicamente a lo establecido en la Convención Internacional de los derechos de las personas con discapacidad, así como a los comentarios que sobre el articulo 12 han realizado diferentes juristas y expertos, como Cabra de Luna, M.A. (2007), García Pons, A. (2008) o Legerén Molina, A. (2012). 
En sentido estricto, la investigación que hemos realizado y de la que, en parte, damos cuenta en este artículo, no se plantea como una investigación que pretende verificar una hipótesis, sino como una indagación sobre la forma de interpretar las consecuencias que se derivan del artículo 12 de la Convención en la forma de aplicar los procedimientos jurídicos de incapacitación y nombramiento de tutores. Para ello se ha tenido en cuenta las legislaciones europeas y se ha preguntado a los expertos (gerentes y directores de las fundaciones tutelares) sobre sus prácticas y la forma de afrontar los cambios y adaptaciones en el ejercicio de la tutela.

En todo caso, la hipótesis implícita de la investigación es que el sistema de apoyos que se ha de prestar a las personas que actualmente son incapacitadas judicialmente tal como lo prestan las entidades tutelares, deberá ser modificado, pasando de ejercer y entender la tutela como sustitución de una persona a una nueva figura en la que el tutor se convierta en un referente de la gestión de apoyos necesarios para garantizar el pleno ejercicio de derechos, al margen de los déficit o limitaciones del sujeto. Es en este sentido en el que se debe entender las orientaciones que se plantean al final del trabajo, referidas a los modelos de intervención centrados en la persona, calidad de vida y el papel de gestor de casos entendido como una modalidad organizativa, aplicable básicamente a las entidades (personas jurídicas) que se encarguen de temas de vigilancia, acompañamiento y apoyo. Obviamente, las actuaciones que las personas físicas deban realizar en el marco de lo que establece el artículo 12 de la Convención, queda fuera de este artículo y no se planteó en la investigación.

Finalmente la investigación concluye presentando alguna propuesta referida a la forma de prestar los apoyos que pueden darse desde las entidades tutelares.

\section{Resultados y discusión}

Los antecedentes del modelo de apoyo a personas con las capacidades modificadas judicialmente

La revisión que actualmente están realizando los países de la Unión Europea sobre sus modelos vigentes de incapacitación y tutela judicial posee precedentes anteriores a lo regulado en la Convención Internacional de los Derechos de las Personas con Discapacidad (CDPD).

En 1999 la Unión Europea elaboró una Recomendación n. ${ }^{\circ}$ R (99) 4 del Comité de Ministros a los Estados miembros sobre los principios referentes a la protección jurídica de los mayores incapacitados, en la que ya se planteaba la 
necesidad de adoptar criterios de flexibilidad en la respuesta a las incapacitaciones con las siguientes medidas:

1. Que las legislaciones nacionales prevean un marco legislativo suficientemente flexible para admitir varias respuestas jurídicas.

2. Que la legislación ofrezca medidas de protección u otros mecanismos jurídicos simples y poco onerosos.

3. Que se arbitren medidas que no restrinjan la capacidad jurídica de la persona, evitando designar representantes dotados de poderes permanentes, sino autorizaciones puntuales por parte del tribunal o de otro órgano de la intervención.

4. Que se dicten medidas que obliguen a los representantes a actuar conjuntamente con la persona necesitada de apoyos y tener en cuenta sus deseos.

5. Que se incluyan entre las medidas de protección aquellas decisiones que presentan un carácter menor o rutinario y que afecten a la salud o al bienestar, sin ser necesaria una medida judicial o administrativa de mayor calado.

6. Que siempre que los apoyos y protección puedan ser garantizados por la familia o terceros, no es necesario tomar medidas formales, y en todo caso, si es preciso proponer una incapacitación, ésta se deberá limitar, controlar y vigilar para que sus efectos no anulen la capacidad de la persona.

Otro ejemplo más reciente es la Resolución 1642 (2009) de la Asamblea Parlamentaria: «Acceso a los derechos para las personas con discapacidad y su participación plena y activa en la sociedad», adoptada el 26 de enero de $2009^{4}$. Desde entonces, la Unión Europea ha promulgado diversas normas, dictámenes, recomendaciones y resoluciones relacionados con las personas con discapacidad y/o las enfermedades relacionadas con los procesos de envejecimiento que tienen que ver con esta materia.

En el año 2012, desde la consideración del precepto que encierra el artículo 12 de la CDPD, el Comisario para los Derechos Humanos de la Unión Europea publica un documento temático, con el fin de contribuir al debate y la reflexión sobre estas cuestiones titulado ¿Quién debe decidir? Derecho a la

4. Cabe mencionar, asimismo, la Recomendación Rec (2006) 5 del Comité de Ministros a los $E^{o s}$ miembros sobre el Plan de Acción del Consejo de Europa para la promoción de derechos y la plena participación de las personas con discapacidad en la sociedad: mejorar la calidad de vida de las personas con discapacidad en Europa 2006-2015, párrafo 2.2 
capacidad jurídica de las personas con discapacidad intelectual y psicosocial ${ }^{5}$ en el que aparecen las siguientes recomendaciones:

1. Ratifiquen la Convención y su Protocolo Facultativo.

2. Revisen la legislación vigente sobre la capacidad jurídica a la luz de las normas de derechos humanos vigentes en la actualidad, y haciendo particular referencia al artículo 12 de la Convención. La revisión debería permitir identificar y subsanar los posibles defectos y lagunas que privan a las personas con discapacidad de sus derechos humanos en relación con la legislación referente, inter alia, a la tutela, el derecho de voto, y la atención y el tratamiento psiquiátricos obligatorios.

3. Consigan la abolición de los mecanismos que prevén la incapacitación total y la tutela plena.

4. Se cercioren de que las personas con discapacidad gozan de derechos de propiedad, incluido el derecho a heredar bienes y a gestionar sus propios asuntos económicos, el derecho a una vida familiar, a aceptar o rechazar intervenciones médicas, a votar, a asociarse libremente y a acceder a la justicia en pie de igualdad con los demás. No se debería privar a nadie automáticamente de estos derechos debido a una deficiencia o discapacidad, o por el hecho de encontrarse bajo un régimen de tutela.

5. Revisen los procedimientos judiciales para garantizar que una persona que haya sido colocada bajo un régimen de tutela tenga la posibilidad de entablar acciones legales en contra de la tutela o de la forma en que ésta se administra, siempre y cuando los regímenes de tutela sigan siendo válidos.

6. Pongan fin a la colocación «voluntaria» de personas en sectores cerrados de hospitales psiquiátricos y en centros de cuidados sociales contra la voluntad de la persona, pero con el consentimiento de los tutores o representantes locales. La colocación en dichos entornos sin el consentimiento del interesado siempre debería considerarse una privación de libertad y estar sujeta a las salvaguardias establecidas en virtud del artículo 5 del Convenio Europeo de Derechos Humanos.

7. Conciban alternativas apoyadas en relación con la toma de decisiones para aquellos que desean recibir asistencia al tomar sus decisiones o al

5. Comisario para los Derechos Humanos de la Unión Europea (2012): ¿Quién debe decidir? Derecho a la capacidad jurídica de las personas con discapacidad intelectual y psicosocial. Documento temático por el Comisario para los Derechos Humanos. CommDH/ Issue Paper (2012)2. 
comunicarlas a los demás. Dichas alternativas deberían ser fácilmente accesibles para aquéllos que las necesitan y deberían proporcionarse sobre una base voluntaria.

8. Establezcan salvaguardias sólidas con el fin de garantizar que todo apoyo prestado respeta a la persona que lo recibe y sus preferencias, es ajeno a todo conflicto de intereses y se somete a una revisión judicial regular. El interesado debería tener derecho a participar en todo procedimiento de revisión, así como el derecho a una representación legal adecuada.

9. Establezcan la obligación jurídica de las autoridades gubernamentales y locales, de la judicatura, y de los proveedores de atención de salud y de servicios financieros, de seguros y de otro tipo, de ofrecer ajustes razonables a las personas con discapacidad que desean acceder a sus servicios. Los ajustes razonables comprenden el suministro de información fácil de comprender y la aceptación de una persona de apoyo que comunique la voluntad del interesado.

10. Logren la participación activa de las personas con discapacidad intelectual y psicosocial, y de las organizaciones que les representan, en el proceso de reforma de la legislación sobre la capacidad jurídica, y de concepción de alternativas respaldadas en relación con la toma de decisiones.

En julio de 2013, la Agencia Europea de Derechos Fundamentales (FRA UE) emitió un informe sobre la capacidad jurídica y la incapacitación judicial, como culminación de un proyecto de investigación de dos años que coordinó la Fundación Centro de Defensa de la Discapacidad Mental (MDAC) ${ }^{6}$. El informe realiza un análisis jurídico comparado de las leyes sobre capacidad jurídica en los Estados miembros de la Unión Europea, sobre un trabajo de campo realizado en nueve países. El informe también recoge testimonios de primera mano de personas con discapacidad sobre el ejercicio de la capacidad jurídica con plena autonomía. Asimismo, sugiere que los gobiernos deben respetar la autonomía, la voluntad y las preferencias de las personas con

6. Centro de Defensa de la Discapacidad Mental (MDAC): es una organización internacional de derechos humanos que promueve los derechos de los niños y adultos con discapacidad intelectual y discapacidades psicosociales. MDAC promueve la igualdad y la inclusión social a través del litigio estratégico, la promoción, la investigación y el monitoreo y la creación de capacidad. MDAC opera a nivel mundial, así como los niveles regionales y nacionales en Europa y África. MDAC tiene su sede en Budapest, Hungría y fue registrada como una fundación de la capital Tribunal Budapest (número de registro 8689), en noviembre de 2002. 
discapacidad que son representados o de aquellos que necesitan ayuda en la toma de decisiones, de conformidad de las leyes y políticas sobre capacidad jurídica y con el Comité sobre los Derechos de las Personas con Discapacidad de Naciones Unidas (CDPD Committe).

De los 28 Estados miembros de la Unión Europea, 25 han ratificado la $C D P D$, así como la Unión Europea en sí misma. Finlandia, Irlanda y los Países Bajos han firmado pero no ratificado. De los 47 Estados miembros del Consejo de Europa, 38 han ratificado y 7 han firmado. Hay dos Estados que no son miembros de Europa (Liechtenstein y Suiza) que ni han firmado ni ratificado la Convención.

Todo ello hace considerar que la protección jurídica de las personas con las capaces jurídicas modificadas no necesariamente ha de ser garantizada a través de la incapacitación total y del nombramiento de tutores que sustituyan y representen a la persona en todos aquellos actos que la ley deja suspendidos.

La CDPD ha supuesto un avance significativo en esta tendencia de acción jurídico-social, puesto que insta a los Estados Partes a adoptar las medidas pertinentes (y por tanto, también jurídico-legislativas) para que las personas con discapacidad reciban el apoyo que puedan necesitar para ejercitar su capacidad jurídica y el ejercicio de la capacidad jurídica no es otra cosa que la «capacidad de ejercicio» o «capacidad de obrar».

El modelo de Naciones Unidas de apoyo a las personas con las capacidades modificadas judicialmente

El sistema de protección que establece la CDPD, adoptada por Naciones Unidas el 13 de diciembre de 2006 (ratificada por España en 2008,) abandona el llamado «modelo médico o rehabilitador», al que se confiere un carácter residual, toda vez que conlleva una limitación excesiva, e incluso absoluta, de la capacidad de obrar de aquellas personas con alguna discapacidad física, intelectual o psicosocial, impidiéndoles la realización de toda clase de actos de carácter personal y patrimonial, sustituyéndoles en la toma de las decisiones.

Este sistema es contrario al que se establece en el artículo 12 de la CDPD que, bajo el título «igual reconocimiento como persona ante la Ley», reafirma que las personas con discapacidad tienen derecho al reconocimiento de su personalidad jurídica en igualdad de condiciones con las demás, debiéndose asegurar que en todas las medidas relativas al ejercicio de la capacidad jurídica se proporcionen salvaguardias adecuadas y efectivas para impedir los abusos, de conformidad con el Derecho Internacional en materia de derechos humanos. Estas salvaguardias asegurarán que las medidas relativas al ejercicio de la capacidad 
jurídica respeten los derechos, la voluntad y las preferencias de las personas, que no haya conflicto de intereses ni influencia indebida, que sean proporcionales $y$ adaptadas a las circunstancias de las personas, que se apliquen en el plazo más corto posible y que estén sujetas a exámenes periódicos por parte de una autoridad o un órgano judicial independiente e imparcial. Las salvaguardias serán proporcionales al grado en que dichas medidas afecten a los derechos e intereses de las personas.

El artículo 12 de la CDPD adopta el modelo denominado «social» de discapacidad, mediante el cual las personas que resulten afectadas por la modificación de su capacidad, han de disponer de los apoyos o de la asistencia necesaria para la toma de decisiones concretas, de tal modo que no se les prive de su capacidad de forma absoluta. La aplicación de este modelo constituye un reto en el ámbito de la legalidad vigente, pues supone, no sólo la aproximación de los tradicionales conceptos de capacidad jurídica y capacidad de obrar, sino que incide en la expresada regulación sustantiva y procesal sobre la capacidad de las personas, basada en la figura tradicional de la incapacitación y en el sistema tutelar como mecanismo sustitutivo de la capacidad de obrar. Ahora se opta por una nueva herramienta que se sustenta en un sistema de apoyos, el cual se proyecta sobre las circunstancias específicas de la persona con discapacidad en relación con el acto o negocio concreto que se ha de realizar.

Como señala Manuel Martín-Granizo Santamaría, Fiscal Superior de la Fiscalía de Castilla y León, la cuestión de la capacidad jurídica requiere de diversas modificaciones legislativas, pero su aplicación no implica la derogación de la regulación vigente en la actualidad, toda vez que la interpretación realizada por el Tribunal Constitucional se orienta a compatibilizar dicha regulación con los postulados y principios informadores de la CDPD.

En la STC 174/2002, de 9 de octubre, se expresa que el derecho a la personalidad jurídica del ser humano, consagrado en el artículo 6 de la Declaración Universal de los Derechos Humanos de 10 de diciembre de 1948, lleva implícito el reconocimiento del derecho a la capacidad jurídica de la persona, por lo que toda restricción o limitación de su capacidad de obrar afecta a la dignidad de la persona y a los derechos inviolables que le son inherentes, así como al libre desarrollo de la personalidad (artículo 10.1 Constitución Española). En consecuencia, la declaración de incapacitación de una persona sólo puede acordarse por sentencia judicial en virtud de las causas establecidas en la Ley (artículo 199 CC), mediante un procedimiento en el que se respeten escrupulosamente los trámites o diligencias que exigía el artículo 208 del Código Civil (y que en la actualidad se imponen en el vigente artículo 759 
Ley de Enjuiciamiento Civil -LEC-) que, en la medida en que van dirigidas a asegurar el pleno conocimiento por el órgano judicial de la existencia y gravedad de las enfermedades o deficiencias persistentes de carácter físico o psíquico que concurren en el presunto incapaz y que le inhabilitan para gobernarse por sí mismo, que son la causa y fundamento de su incapacitación (arts. 199 y 200 CC), se erigen en garantías esenciales del proceso de incapacitación.

La incapacitación total sólo deberá adoptarse cuando sea necesario para asegurar la adecuada protección de la persona con enfermedad mental permanente, pero deberá determinar la extensión y límites de la medida y deberá ser siempre revisable. Como señala la STS 282/2009, de 29 de abril, el sistema de protección establecido en el Código Civil sigue vigente, aunque, para adecuar su interpretación a la CDPD, habrá de tenerse siempre en cuenta que las personas siguen siendo titulares de sus derechos fundamentales y que la incapacitación total constituye esencialmente una forma de protección, la cual deberá acordarse únicamente en supuestos excepcionales, cuando resulte estrictamente necesaria.

Por tanto, puede afirmarse que, sin perjuicio de las modificaciones que procedan para su total adaptación, nada impide que la legislación sustantiva y procesal vigente relativa a la determinación de la capacidad de las personas pueda interpretarse y aplicarse con adecuación a las previsiones de la CDPD.

Evolución de la población con incapacitación judicial en castilla y león. Análisis de la fiscalía

Las Memorias de la Fiscalía nos muestran la acción judicial en materia de «modificación de la capacidad jurídica». Aunque los datos globales no dan información detallada sobre las características de las personas sometidas a este proceso en función de la edad o la causa que motiva el procedimiento, sí podemos conocer el número de procesos que anualmente se incoan en Castilla y León y su distribución provincial.

La tabla n. ${ }^{\circ} 1$ refleja una tendencia bastante similar de procesos y sentencias anuales. La media de sentencias anuales asciende a 1.522, mientras que la media de procedimientos incoados es 2.586. Estas cifras exponen que, de media, el porcentaje de sentencias favorables respecto a los procesos incoados en Castilla y León es del 58,9\% (tomando como referencia los últimos 5 años analizados). 
92 Jose Daniel Rueda Estrada; José Juan Zurro Muñoz; Jose Carlos Fernández Sanchidrián

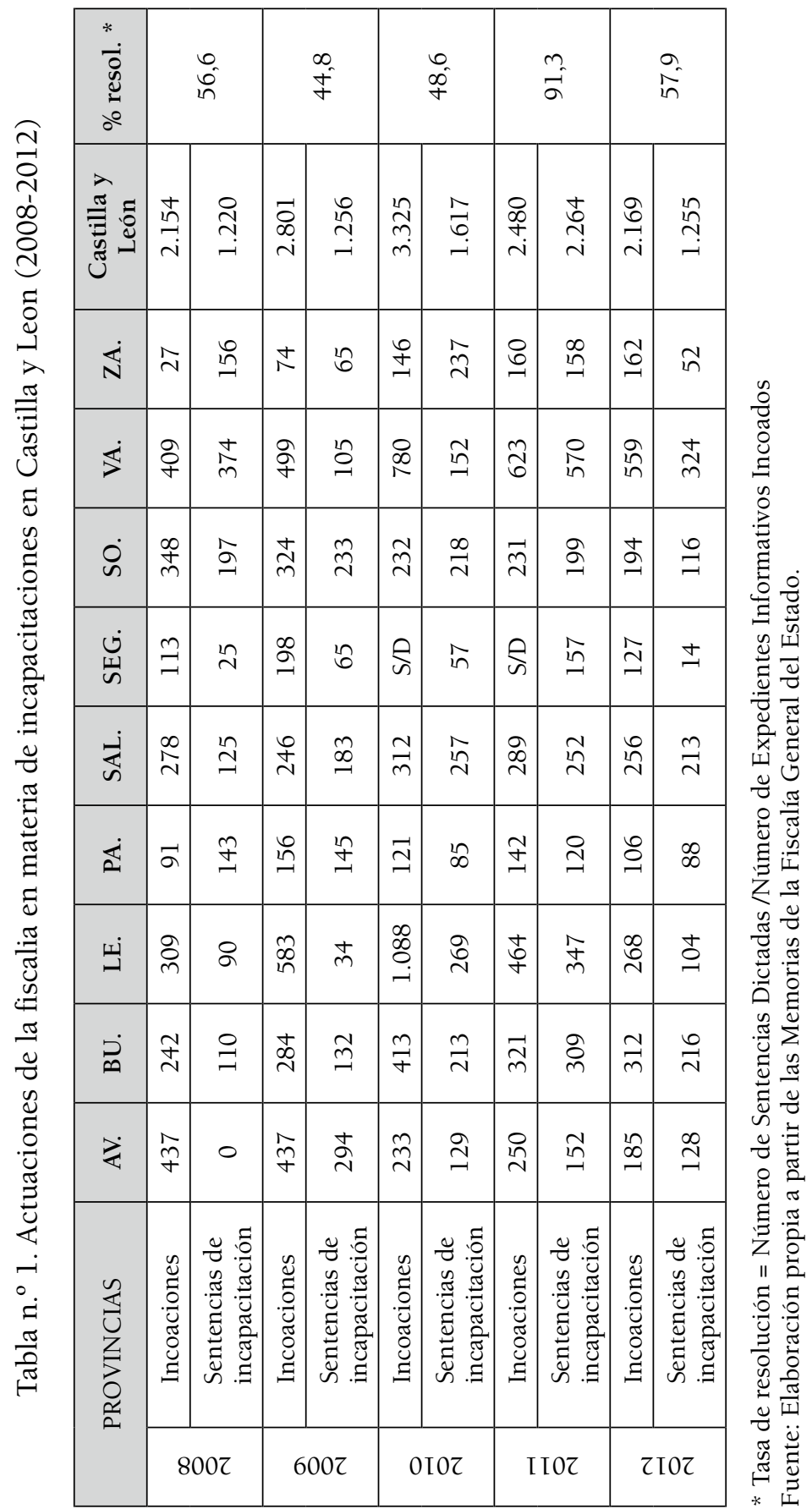

Alternativas. Cuadernos de Trabajo Social, 21, 2014, pp. 81-118 - ISSN 1133-0473 
Las diligencias informativas que llegan a convertirse en sentencias de incapacitación están en una proporción de 56,6\%en el año 2008 para situarse en $57,9 \%$ en 2012. De esta variación destaca el año 2011 en el que el 91,3\% de los expedientes informativos concluyeron con una sentencia estimatoria.

A la luz de los datos recogidos sobre sentencias de incapacitación y dictámenes de expedientes de tutela y curatela, cruzados con los cargos tutelares que las entidades sociales asumen cada año, se puede precisar que más del $80 \%$ de los cargos tutelares en Castilla y León son asumidos por personas físicas, las previstas en el artículo 234 del Código Civil (Ej.- familiares). Las personas incapacitadas de Castilla y León que anualmente terminan siendo tuteladas por alguna de las entidades sociales acogidas al artículo 242 del Código Civil (FUNDAMAY, FUTUDIS Y FECLEM) y al artículo 239 (FASTCYL) son un número minoritario, respecto a las sentencias dictadas. Según los datos obtenidos, en 2012 hubo 169 nuevas personas con cargos tutelares asumidos por las entidades, de las 1.255 sentencias de incapacitación, es decir, el 13,5\% del total.

Tabla n. ${ }^{\circ}$ 2. Expedientes de tutela y curatela en castilla y leon según las memorias de la fiscalía general del estado (2008-2012)

\begin{tabular}{|l|c|c|c|c|c|}
\hline \multicolumn{1}{|c|}{ Provincia } & AÑO 2008 & AÑO 2009 & AÑO 2010 & AÑO 2011 & AÑO 2012 \\
\hline AVILA & 50 & 42 & 78 & S/D & 81 \\
\hline BURGOS & 160 & 350 & 214 & S/D & 1.120 \\
\hline LEON & 73 & S/D & 484 & S/D & 425 \\
\hline PALENCIA & 2 & 620 & 693 & S/D & 73 \\
\hline SALAMANCA & 6 & 635 & 792 & S/D & 759 \\
\hline SEGOVIA & 22 & 47 & 50 & S/D & 26 \\
\hline SORIA & 11 & 0 & 25 & S/D & 15 \\
\hline VALLADOLID & 340 & 2.208 & 347 & S/D & 935 \\
\hline ZAMORA & 28 & 460 & 377 & S/D & 447 \\
\hline TOTAL & 692 & 4.362 & 3.060 & S/D & 3.881 \\
\hline
\end{tabular}

Fuente: Elaboración propia a partir de las Memorias de la Fiscalía General del Estado. 
A nadie se le oculta que muchas familias que conviven con personas que presentan discapacidades susceptibles de incapacitación judicial atienden a estas personas, sin alterar o modificar su capacidad de obrar. De esta manera, familiares o personas con las que se mantiene una relación directa, no siempre inician un procedimiento de incapacitación. Esto puede explicar el que no se incremente de modo significativo los procesos anuales de incapacitación incoados, aun cuando se registren incrementos en las cifras de envejecimiento y de personas con enfermedades que aparecen con la edad, y que pueden ser causa de incapacitación. A este tipo de explicaciones habrá que sumar otras relacionadas con las infraestructuras y medios del poder judicial.

Las entidades de acción tutelar en Castilla y León: Futudis, Feclem, Fundamay $y$ Fastcy

Si se entiende que la tutela es una figura similar a la «patria potestad», parece obvio que deben ser las personas físicas las que, en principio, han de hacerse cargo de las personas incapacitadas, ya que esto significa una especial protección tanto de la persona como de su patrimonio o bienes. Así era considerado en el anterior Código Civil que regulaba esta materia, al instituir y hacer descansar la misma sobre la familia e instituir como figura de garantía al Consejo de Familia y al protutor.

No obstante, la Ley 13/1983, de 24 de octubre, de reforma del Código Civil en materia de incapacitación y tutela plantea que no solo las personas físicas están llamadas a asumir los cargos de tutela o curatela, sino que también las personas jurídicas (entidades públicas o privadas), pueden hacerse cargo de esta protección, siempre que las personas físicas no existan, se excusen, no reúnan condiciones de garantía o el Juez estime que la persona jurídica ofrece una mayor garantía para el tutelado. Entre otras, las fundaciones tienen la ventaja de que tradicionalmente son las que se han puesto al servicio de las clases y personas más necesitadas para darles protección y amparo; ofrecen una mayor estabilidad, ya que sobrevive a los fundadores; aunque pueda extinguirse no muere, como ocurre con las personas físicas, ni está sometida a los cambios de opinión que establezcan los socios como ocurre con las asociaciones, ya que el protectorado ampara que se respete la voluntad de los fundadores.

En Castilla y León el ejercicio de las funciones tutelares respecto a personas incapacitadas es desempeñado por las siguientes entidades: 


\begin{tabular}{|l|l|l|}
\hline \multirow{5}{*}{$\begin{array}{l}\text { Iniciativa } \\
\text { privada }\end{array}$} & $\begin{array}{l}\text { Fundación Tutelar } \\
\text { Castellano Leonesa de } \\
\text { Personas con Discapacidad } \\
\text { Intelectual (FUTUDIS). }\end{array}$ & $\begin{array}{l}\text { Para personas con discapacidad intelectual. } \\
\text { Constituida en 1990 a iniciativa de las } \\
\text { Asociaciones de personas con discapacidad } \\
\text { intelectual integradas en FEAPS Castilla y } \\
\text { León. }\end{array}$ \\
\cline { 2 - 3 } & $\begin{array}{l}\text { Fundación Tutelar de } \\
\text { Castilla y León (FECLEM). }\end{array}$ & $\begin{array}{l}\text { Personas con enfermedad mental. } \\
\text { Constituida en 2001, mediante } \\
\text { Resolución a iniciativa de la Federación } \\
\text { de Asociaciones de Familiares y Personas } \\
\text { con Enfermedad Mental de Castilla y León } \\
\text { (FEAFES). }\end{array}$ \\
\cline { 2 - 3 } & $\begin{array}{l}\text { Fundación Castellano } \\
\text { Leonesa para la Tutela } \\
\text { de las Personas Mayores } \\
\text { (FUNDAMAY). }\end{array}$ & $\begin{array}{l}\text { Personas mayores. Constituida en 2002, } \\
\text { impulsada por la Asociación Tutelar de } \\
\text { Personas Mayores (con origen en 1996). }\end{array}$ \\
\hline \multirow{2}{*}{$\begin{array}{l}\text { Iniciativa } \\
\text { Pública }\end{array}$} & $\begin{array}{l}\text { Fundación Acción Social } \\
\text { y Tutela de Castilla y León } \\
\text { (FASTCyL) }\end{array}$ & $\begin{array}{l}\text { Dispensa atención y protección jurídico- } \\
\text { social a personas incapacitadas legalmente } \\
\text { y en situación de desamparo. Creada en } \\
\text { 2009. }\end{array}$ \\
\hline
\end{tabular}

Las actividades de la tutela, curatela, defensa judicial y administración judicial alcanzaron un total de 1.522 casos acumulados en 2012. Las Fundaciones privadas de Tutela gestionaron 1.334 expedientes de personas en situación legal de incapacitación. Por su parte, la Fundación Acción Social y Tutela de Castilla y León (FASTCyL) colaboró en 188 casos financiando las acciones de protección que venían desarrollando entidades privadas colaboradoras, además de la colaboración en la gestión patrimonial de tutelados por la administración.

Tabla n. ${ }^{\circ}$ 3. Personas con incapacitación judicial atendidas por entidades tutelares de castilla y león (2012)

\begin{tabular}{|l|c|c|c|}
\hline & De 18 a 64 años & De 65 y más & TOTAL \\
\hline FASTCyL & 147 & 41 & 188 \\
\hline FUTUDIS & 407 & - & 407 \\
\hline FECLEM & 562 & - & 562 \\
\hline FUNDAMAY & - & 365 & 365 \\
\hline Total & 1.116 & 406 & 1.522 \\
\hline
\end{tabular}

Fuente: Gerencia de Servicios Sociales de Castilla y León. 
Los datos anteriores se refieren a los cargos activos, acumulados en los últimos años. A lo largo del año, cada entidad tutelar experimenta un número determinado de altas y bajas en los cargos tutelares que acepta (que, por otro lado, no son todos los propuestos por los juzgados) por diversos motivos (Ej.- apertura de un nuevo expediente a mitad de año, defunción de un cargo tutelar, etc.). Conviene conocer los cargos que tramita cada entidad tutelar en un año.

Tabla n. ${ }^{\circ}$ 4. Cargos tutelares aceptados en el año por las entidades tutelares de Castilla y León (2008-2012)

\begin{tabular}{|c|c|c|c|c|c|c|}
\hline 2008 & \begin{tabular}{|c} 
Cargos \\
propuestos \\
\end{tabular} & $\begin{array}{c}\text { Cargos } \\
\text { aceptados }\end{array}$ & Cerrados & $\begin{array}{c}\text { Cargos al } \\
\text { inicio }\end{array}$ & $\begin{array}{c}\text { Cargos al } \\
\text { final }\end{array}$ & TOTAL \\
\hline FUTUDIS & 72 & 48 & 4 & 266 & 310 & 44 \\
\hline FECLEM & 87 & 87 & 0 & 209 & 250 & 41 \\
\hline FUNDAMAY & 108 & 95 & 85 & 269 & 279 & 10 \\
\hline \multicolumn{6}{|c|}{ TOTAL 2008} & 95 \\
\hline 2009 & $\begin{array}{c}\text { Cargos } \\
\text { propuestos }\end{array}$ & $\begin{array}{c}\text { Cargos } \\
\text { aceptados }\end{array}$ & Cerrados & $\begin{array}{c}\text { Cargos al } \\
\text { inicio }\end{array}$ & $\begin{array}{c}\text { Cargos al } \\
\text { final }\end{array}$ & TOTAL \\
\hline FUTUDIS & 62 & 19 & 8 & 310 & 321 & 11 \\
\hline FECLEM & 125 & 125 & 0 & 250 & 275 & 25 \\
\hline FUNDAMAY & 171 & 147 & 104 & 278 & 321 & 43 \\
\hline \multicolumn{6}{|c|}{ TOTAL 2009} & 79 \\
\hline 2010 & \begin{tabular}{|c} 
Cargos \\
propuestos
\end{tabular} & $\begin{array}{c}\text { Cargos } \\
\text { aceptados }\end{array}$ & Cerrados & $\begin{array}{c}\text { Cargos al } \\
\text { inicio }\end{array}$ & $\begin{array}{c}\text { Cargos al } \\
\text { final }\end{array}$ & TOTAL \\
\hline FUTUDIS & 66 & 32 & 5 & 321 & 348 & 27 \\
\hline FECLEM & 91 & 91 & 0 & 275 & 309 & 34 \\
\hline FUNDAMAY & 169 & 136 & 104 & 319 & 351 & 32 \\
\hline \multicolumn{6}{|c|}{ TOTAL 2010} & 93 \\
\hline 2011 & $\begin{array}{c}\text { Cargos } \\
\text { propuestos }\end{array}$ & $\begin{array}{c}\text { Cargos } \\
\text { aceptados }\end{array}$ & Cerrados & $\begin{array}{c}\text { Cargos al } \\
\text { inicio }\end{array}$ & $\begin{array}{l}\text { Cargos al } \\
\text { final }\end{array}$ & TOTAL \\
\hline FUTUDIS & 62 & 33 & 11 & 348 & 369 & 21 \\
\hline FECLEM & 109 & 109 & 0 & 309 & 341 & 32 \\
\hline FUNDAMAY & 143 & 70 & 94 & 351 & 327 & -24 \\
\hline FASTCyL* & 98 & 98 & S/D & S/D & 98 & 98 \\
\hline \multicolumn{6}{|c|}{ TOTAL 2011} & 127 \\
\hline
\end{tabular}




\begin{tabular}{|c|c|c|c|c|c|c|}
\hline 2012 & $\begin{array}{c}\text { Cargos } \\
\text { propuestos }\end{array}$ & $\begin{array}{c}\text { Cargos } \\
\text { aceptados }\end{array}$ & Cerrados & $\begin{array}{c}\text { Cargos al } \\
\text { inicio }\end{array}$ & $\begin{array}{c}\text { Cargos al } \\
\text { final }\end{array}$ & TOTAL \\
\hline FUTUDIS & 64 & 31 & 11 & 369 & 389 & 20 \\
\hline FECLEM & 178 & 178 & 0 & 341 & 362 & 21 \\
\hline FUNDAMAY & 162 & 133 & 95 & 327 & 365 & 38 \\
\hline FASTCyL & 90 & 90 & S/D & 98 & 188 & 90 \\
\hline \multicolumn{6}{|c|}{ TOTAL 2012} & 169 \\
\hline
\end{tabular}

* FASTCyL no dispone de datos hasta el año 2011.

Fuente: Elaboración a partir de los datos facilitados por las entidades tutelares de Castilla y León.

Además de los programas propios de la tutela estas fundaciones han elaborado un amplio Catálogo de Servicios destinados a velar por la persona tutelada, o sometida a un plan de apoyos bajo vigilancia judicial, con la finalidad de hacer todo lo necesario para el desarrollo integral y la mejor integración en la sociedad de la citada persona.

Para la elaboración de este epígrafe se ha contado con la aportación de las fundaciones tutelares de Castilla y León, quienes han aportado, desde su experiencia aquellas actuaciones que de manera específica realizan como consecuencia de su propia misión y razón de ser.

Las fundaciones tutelares, en cuanto servicios especializados en materia de protección jurídica y tutela a las personas con enfermedad mental, discapacidad intelectual o enfermedades propias del envejecimiento, diferencian aquellos servicios que forman parte de su propia misión, como son los referidos al ejercicio tutelar, y que se centran en la protección, defensa y apoyo de las personas tuteladas, los cuales se derivan y vienen recogidos en los mapas de procesos: estratégicos, operativos y de apoyo, de aquellos otros servicios que complementan la misión específica y que contribuyen a crear sinergias con otros recursos y servicios.

En este escenario, se señala dos grandes tipos de servicios: los referidos a servicios pretutelares y los derivados del ejercicio tutelar transversal. A estos habría que añadir los servicios derivados de las emergencias o situaciones críticas que se deben afrontar en el curso devenir del servicio tutelar. De manera sintética enumeramos, los siguientes servicios: 
A. Respecto a la persona apoyada o asistida

1. Servicio de estudio y análisis de las capacidades de la persona a proteger.

2. Servicio de planificación de la intervención de acuerdo con el estudio anterior.

3. Servicio de gestión, orientado a preparar y presentar solicitudes de servicios y recursos sociales, sanitarios, laborales, residenciales, etc., como derechos a los que la persona sometida a apoyos no puede exigir o tramitar por carecer de información y capacidad.

4. Servicio de evaluación centrado en el logro y resultados de las acciones emprendidas o programas de intervención en las diferentes áreas: personal, patrimonial-económica, relacional, laboral, sanitaria, etc.

5. Servicio de documentación para informar a la autoridad judicial de la evolución del estado de la persona a proteger, teniendo en cuenta los avances en la autonomía y capacidades, como en el caso de que la situación requiera ampliar el campo de apoyos a prestar por la evolución y deterioro de la situación que padece la persona protegida.

6. Servicio de orientación sobre recursos institucionales y asociativos que puedan contribuir a mejorar, mantener o retardar el deterioro, en aquellas personas mayores de edad con déficits importantes.

7. Servicio centrado en la administración de bienes.

8. Servicio de asistencia jurídica.

9. Servicio de emergencias y urgencias.

Además de los servicios que hemos referenciado, cabe destacar, otras actuaciones que engloban también el Catálogo y la Cartera de Servicios de las fundaciones tutelares, entre los que enumeramos:

B. Servicios orientados a familiares

- Servicio de información y asesoramiento: gestión de ayudas y recursos, conocimientos sobre la tramitación de procedimientos, procesos de acompañamiento secuenciado, etc.

- Servicio de apoyo a la gestión de la tarea tutelar, cuando aceptan el cargo de tutores personas físicas.

C. Servicios orientados a profesionales y organizaciones

- Servicio de información y asesoramiento.

- Servicio de formación sobre las tareas a desarrollar.

- Servicio de estudio sobre capacidades. 
- Servicio de planificación de apoyos y planes de intervención.

- Servicio de evaluación: preparar herramientas de evaluación específicas.

- Servicio de formación interna y mejora continua -análisis de necesidades formativas-.

D. Servicios orientados a empresarios

- Servicio de orientación y asesoramiento: información sobre contratación y adaptación de puestos de trabajo.

- Servicios de formación centrados en la adaptación de la persona con discapacidad al puesto de trabajo y en el acogimiento del resto de trabajadores de la empresa.

E. Servicios de voluntariado

- Servicio de captación de voluntarios: centros educativos, asociaciones, colectivos de familiares, colectivos profesionales...

- Servicio de formación y seguimiento de los voluntarios.

- Servicio de formación basado en la aplicación de NT.

- Servicio de evaluación y análisis de necesidades.

F. Servicios orientados a la población en general

Una panoramica sobre el proceso de incapacitación y tutela en diversos paises europeos

Para el estudio comparado entre países hemos procedido analizando la legislación existente y recabando de los embajadores en España una información más precisa. Para ello les hemos planteado las siguientes cuestiones:

1. El ordenamiento jurídico del país, ¿Mantiene la fórmula de incapacitación judicial como medida de protección hacia personas que no pueden gobernarse por padecer alguna enfermedad de carácter permanente que les impida ejercer sus derechos con todas las garantías, o se ha producido un cambio en la concepción sobre esta materia para adaptarse a lo establecido en la Convención sobre Derechos de las Personas con Discapacidad, de manera que no se producen incapacitaciones para que la persona no pierda su capacidad de obrar, sustituyendo la tutela por apoyos centrados en las personas con limitaciones?

2. En caso de que se haya producido un cambio legislativo, ¿Podría indicarnos la referencia legal? 
3. La legislación que rige esta materia en el país, ¿Contempla la posibilidad de que los apoyos a las personas con dificultades para gobernar su vida, puedan ser prestados por organizaciones o entidades jurídicas (asociaciones, fundaciones, voluntariado) además de por personas físicas?

4. En el supuesto de que los apoyos los puedan prestar entidades, ¿Es esta una medida excepcional o se suele aplica como mecanismo de subsidiariedad cuando se carece de personas físicas idóneas?

5. ¿Conoce si los sistemas judiciales que intervienen en esta materia, describen con minuciosidad las tareas y responsabilidades que la persona (física o jurídica) debe realizar para prestar los apoyos necesarios a la persona incapaz o con graves limitaciones?

6. ¿El sistema judicial exige a estas figuras de apoyo rendir cuentas de su gestión con carácter obligatorio y temporal?

7. ¿Existen protocolos para el desempeño de estas tareas, por parte de los sistemas jurídicos, para que cada asistente o persona de referencia conozca sus obligaciones y responsabilidades?

8. ¿Existen fórmulas de cooperación público-privada para la gestión de la tutela o protección de personas gravemente afectadas para el desempeño de tareas propias de la vida diaria?

9. ¿Conoce si existen programas de voluntariado para asistir a las personas incapacitadas o sometidas a vigilancia y apoyo para garantizar sus derechos?

10. ¿Con cargo a qué o quienes se imputan los gastos que conlleve la prestación de apoyos para este tipo de personas: presupuestos públicos, patrimonio y haberes de la persona que necesita apoyos, ambos, otras fórmulas?

De la información recibida y del análisis de las distintas legislaciones podemos señalar que el sistema de incapacitación y tutela de España se aleja de algunas de las legislaciones más avanzadas y adaptadas a la Convención, en el sentido de que se plantean alternativas que pasan por no incoar proceso de incapacitación total, sino por prestar apoyos a través de figuras distintas: acompañante, administrador, asistente, etc. La opción sobre el testamento vital o las voluntades anticipadas, sobre todo en aquellas personas que por causas de edad, enfermedad, etc., prevean un futuro incierto se impone como una práctica aconsejable.

De la información recibida, y tras el análisis por países, presentamos a continuación el siguiente resumen: 


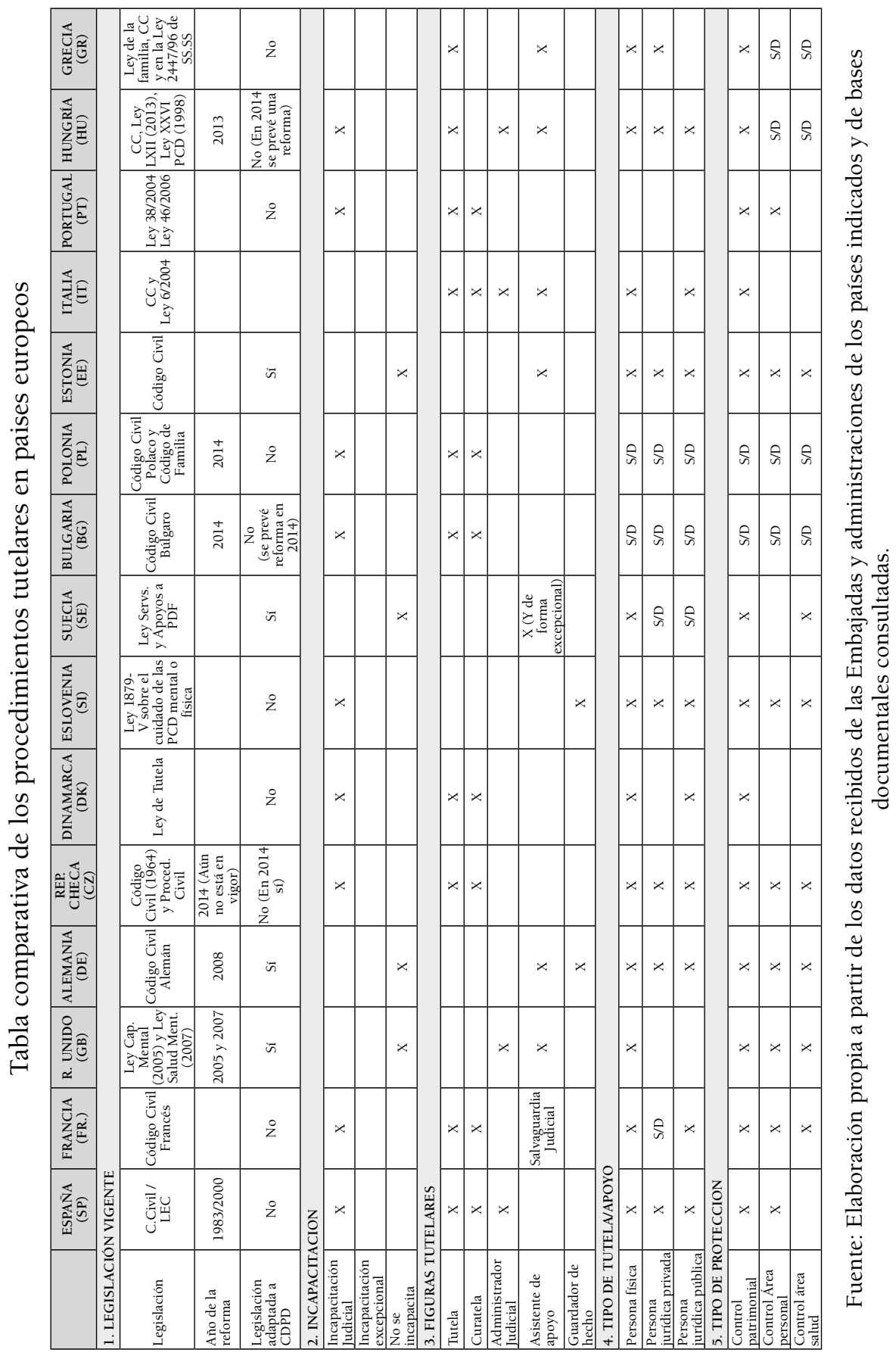

Alternativas. Cuadernos de Trabajo Social, 21, 2014, pp. 81-118 - ISSN 1133-0473 DOI: 10.14198/ALTERN2014.21.05 


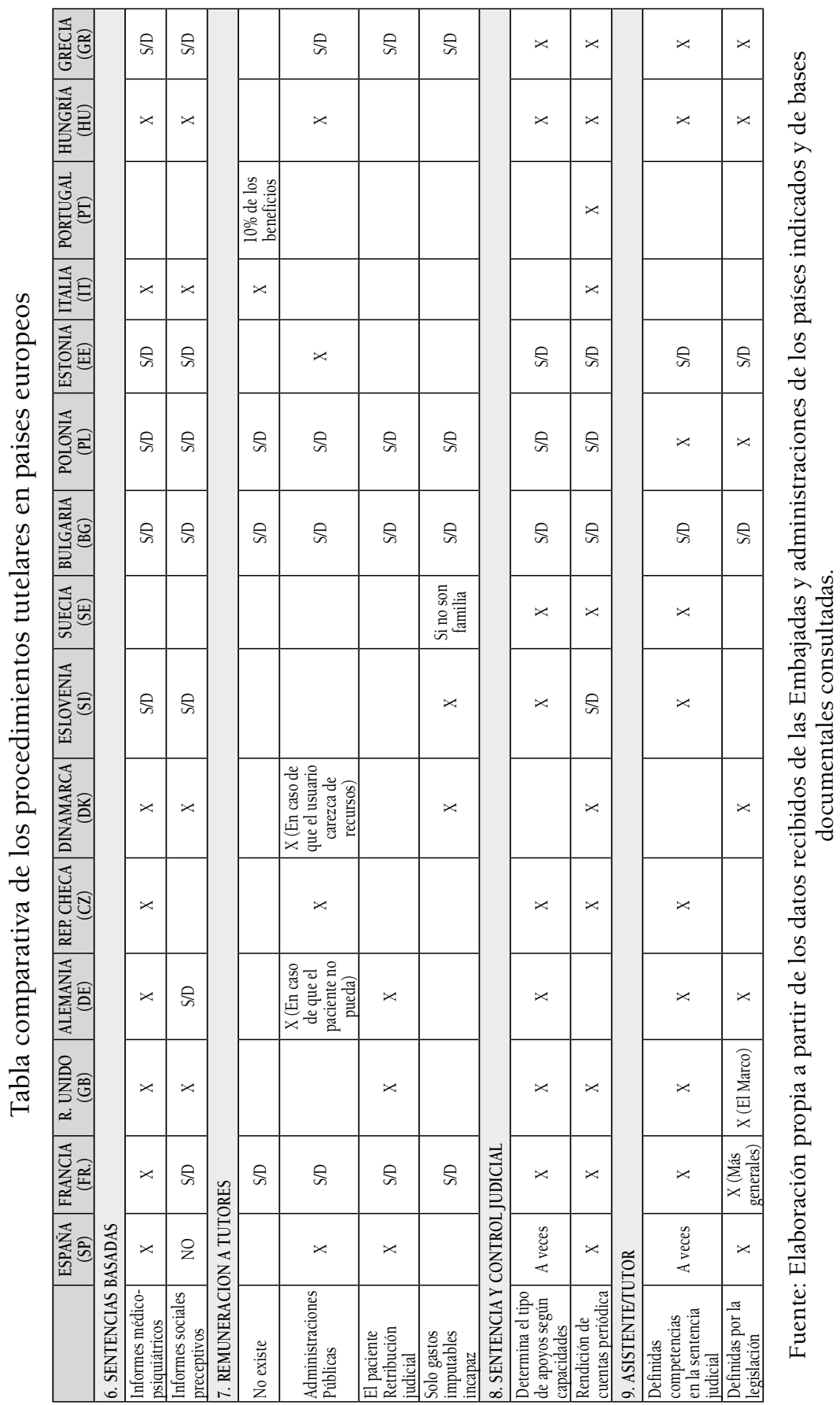

Alternativas. Cuadernos de Trabajo Social, 21, 2014, pp. 81-118 - ISSN 1133-0473 


\section{Interpretación y propuestas}

A partir de las entrevistas mantenidas con los directores gerentes de las entidades tutelares de Castilla y León, el equipo de investigación plantea una serie de consideraciones y de conclusiones que sintetizamos a continuación.

La filosofía que subyace a todo el articulado de la CDPD gira en torno al término y concepto «apoyos». Estos deberán ajustarse o cambiar en la medida en que cambien las situaciones, o se vayan alcanzando las metas planteadas. Es en esta perspectiva donde tiene sentido pensar en modelos de intervención integral centrada en las personas, desde una visión que integre la calidad de vida, la garantía de derechos y las circunstancias personales. Lo apoyos, se orientarán a completar los déficits, a evitar o modificar las circunstancias sociales que impidan el desarrollo y el ejercicio de los derechos con plena capacidad.

Esta perspectiva exige que los sistemas judiciales que intervengan en el proceso de protección de las personas con deficiencias que dificulten alcanzar una vida autónoma en igualdad de derechos que cualquier otro ciudadano, tengan que revisar periódicamente los cambios que se produzcan, para modificar el tipo o intensidad de los apoyos que presten las personas, profesionales o entidades encargadas de proporcionarlos.

Conocer, mediante informes periciales, informes técnicos exigibles a las personas físicas o jurídicas encargadas de prestar los apoyos, los cuales deberían ser elevados al Juez y al Fiscal, puede ser una forma de presentar las rendiciones, sirviendo de base para las decisiones judiciales. Se trata de que el procedimiento, en plena coherencia con lo que impone la Convención, sea capaz de «determinar los apoyos», apoyos que pueden ser de diferente naturaleza: apoyos naturales y apoyos formales.

El primer nivel de los apoyos de las personas con limitaciones o déficits se debe encontrar en el ámbito de las relaciones de proximidad y cercanía, en el nivel del microsistema; nos referimos al apoyo familiar, el del vecino, el amigo o la persona que, en definitiva, actúa como referente en cada caso y situación. Estos apoyos pueden estar previstos y acordados por las propias personas antes de que se encuentren en la situación de déficit o limitación o por las propias familias, y expresado mediante actos formales ante los notarios; es el caso de los testamentos vitales, de voluntades anticipadas, previsto en el ordenamiento jurídico. Estas decisiones adoptadas por la persona con discapacidad, en las que se pueden expresar los tipos de ayuda que se precisan y las personas que pueden o que quieren que se los proporcione, pueden tener trascendencia jurídica. Tales apoyos, decididos por la propia persona 
con discapacidad, podrán ser establecidos bien de manera informal, o bien de manera documental.

El segundo nivel, el de los apoyos formales, es decir, los establecidos de una forma regular, institucional o jurídica, constituyen otro nivel que requiere garantías y controles diferentes. Las entidades y servicios que de forma especializada trabajen con personas que tengan limitadas sus capacidades, tendrán que adaptar sus procesos y procedimientos a mejorar esas limitaciones y a restar las ayudas necesarias, mediante programas personalizados y evaluados. Pero los apoyos no sólo se deben circunscribir a estas entidades sino también a los procesos que las administraciones deben instar para que no se produzcan discriminaciones por padecer una determinada discapacidad o deficiencia, cuando tengan que acudir a estas oficinas para tramitar determinados asuntos (salud, administrativos, laborales, jurídicos...).

Parece obvio pensar en la posibilidad de que cualquier otra persona (autoridad judicial, funcionarios, personal sanitario, docente o de trabajo social, personal evaluador en procedimientos de reconocimiento de discapacidad $u$ otros) pueda comunicar al Juzgado aquellas situaciones en las que entienda adecuado establecer apoyos para personas con discapacidad, tal como lo recoge el actual texto de la Ley de Enjuiciamiento Civil.

Para que este sistema sea garantista y realmente esté centrado en la persona, se requiere un trabajo en red en el que profesionales de diversos perfiles puedan contribuir al estudio, análisis y elaboración de informes que permitan una respuesta judicial adaptada a cada persona y en la que pueda participar también la propia persona con discapacidad o en su defecto los miembros de la red informal o formal que se vienen ocupando de prestarle los apoyos.

De acuerdo a lo anterior, es preciso que la reforma del actual sistema de incapacitación, que deba implementarse tenga claras algunas premisas, tales como las que señalamos a continuación:

- Para proteger los intereses, necesidades y pleno ejercicio de los derechos de las personas, respecto a sí mismos o a los bienes, los apoyos han de garantizar la validez de los actos jurídicos y el derecho a la autonomía, dado que toda persona conserva en igualdad de condiciones la capacidad jurídica y de obra.

- Las personas pueden previamente determinar mediante escritura púbica, el tipo de apoyos que precisa y la forma en que quiere que se le presten.

- Cuando estas circunstancias no existan o no puedan darse debido a la falta o disminución de incapacidades, deberán ser los órganos 
judiciales quienes determinen los poyos precisos, diferenciando aquellos que deban prestarse para ejecutar determinadas actuaciones que puedan poner en situación de riesgo a la propia persona, tales como contratos, compraventas, etc., para evitar posibles abusos por parte de terceros.

- La resolución judicial deberá establecer el programa de apoyos personalizado, con el fin de garantizar el pleno ejercicio de la capacidad jurídica de las personas, sobre todo en el caso en que existan causas que impidan o limiten la adopción libre de decisiones y la persona no hubiera expresado o realizado previamente una designación personal y voluntaria respecto a los apoyos. Estos programas deberán realizarse de acuerdo a las preferencias, valores, estilo de vida de las personas, desde el respeto a su voluntad, teniendo en cuenta el principio de autodeterminación y autonomía, tal como lo expresa la Convención.

- Los apoyos deberán plantearse como medidas y medios para garantizar la capacidad jurídica y no como limitaciones al principio de autonomía.

- El programa de apoyos individualizado que determine el juez deberá señalar a la persona física o jurídica de referencia, a quien se le encargue y responsabilice de prestar o coordinar los apoyos previstos. Esta persona puede ser, si existe, la que el propio interesado o sus representantes, hubieran establecido previamente, sobre todo si está recogido en escritura pública.

- En el caso de que el encargado o el referente de prestar o coordinar los apoyos recaiga en una entidad (por ejemplo una entidad tutelar), existirá un gestor del caso, que deberá garantizar no sólo que la persona recibe los apoyos necesarios, sino también evaluar periódicamente los resultados, avances o retrocesos que experimenta la persona, pudiendo elevar al sistema judicial el informe correspondiente sobre el particular, a fin de continuar o modificar el programa de apoyos.

- El fin o razón de ser de esta persona referente o gestor del caso, no es otra que la de acompañar y asistir de forma activa a la persona apoyada, para que pueda ejercitar, con la máxima autonomía, las propias decisiones. En todo caso, la autoridad judicial deberá determinar, tal como lo establece el actual Código Civil en los artículos 271 y 272 los actos para los que está autorizado a intervenir y los que quedan fuera de su control, de la misma manera que puede determinar quién o quienes no pueden asumir el papel de gestor (artículos 243 y 244 del actual Código Civil). 
La filosofía que emana de la Convención, deberá orientar los cambios en el modelo de tutela que se viene desarrollando actualmente en España. No obstante el cambio y proceso de reforma no significa que algunas de las figuras y planteamiento que están vigentes en la legislación actual hayan de ser necesariamente sustituidas. Es preciso dar continuidad a los trabajos, procesos de protección que se vienen prestando a las personas actualmente sometidas a tutela o curatela, procurando desarrollar nuevas estrategias y servicios en sintonía con lo previsto en la Convención. Es más, pensamos que hay una experiencia de buenas prácticas en temas de tutela, tanto la ejercida por las personas físicas, como sobre todo por las personas jurídicas que deberá ser aprovechada y fortalecida, en cuanto hoy constituyen un recurso especializado e idóneo para garantizar el apoyo y protección de las personas más vulnerables.

Sin duda el cambio legislativo afectará también a muchas de las entidades que hoy prestan apoyos de tutela y ejercen los cargos con alta especialidad; es probable que en sus estatutos haya que modificar algunos artículos para responder mejor a la filosofía de la Convención y avanzar en el modelo de prestación de servicios, mejorando el Catálogo y la Cartera de Servicios.

\section{Una mirada al futuro próximo}

La adaptación de la legislación en materia de tutela e incapacitación a la Convención de las Naciones Unidas para las personas con Discapacidad, implica pasar de un modelo de asistencia y rehabilitador a un modelo social, basado en la autonomía, autodeterminación, en la igualdad, en la promoción, en definitiva a un modelo basado en los derechos de los ciudadanos. Frente a la figura del tutor, que supone ser un «alter ego» de la persona que carece de capacidades o que no puede ejercerlas libremente, porque el juez así lo ha decidido como medida de protección, la figura del acompañante, del prestador de apoyos, va requerir cambios importantes en la misma esencia de estas figuras.

Ninguna persona ha de perder su capacidad jurídica a lo largo de la vida. Pero el cambio de concepción no significa que automáticamente las personas tengan o hayan adquirido todas las capacidades de manera que no necesiten ninguna persona de referencia para que le oriente, defienda o proteja. El cambio está en que ahora se exigirá conocer qué capacidades tienen las personas, cuáles de estas capacidades se pueden ejercer de manera autónoma y sin intermediación y cuáles se encuentran disminuidas y requieren ser revisadas, suplidas, complementadas con los apoyos que otra persona pueda proporcionar.

Los jueces, de acuerdo a la nueva situación ya no pueden sentenciar sobre las capacidades de las personas de manera general, sino que deberán tener que dictar sentencias de protección y determinar qué tipo de apoyos y para qué 
capacidades son necesarios en aquellas personas que padezcan alguna limitación derivada de la enfermedad, del envejecimiento o de déficits congénitos.

En este sentido, las actuales entidades que se encargan de trabajar en los temas de tutela, tendrán que modificar también sus propias prácticas y adaptar sus procedimientos a la nueva visión y concepción.

Indefectiblemente será preciso realizar un trabajo personalizado, a través del modelo de intervención centrado en la persona, lo que significa partir no solo del conocimiento de las sentencias judiciales en las que se determine sobre qué limitaciones o déficit de capacidad hay que intervenir o acompañar a la persona, sino determinar cuáles son los apoyos a prestar en todas las esferas de la persona: para favorecer su autonomía, su capacidad de autodeterminación, de inserción social y laboral, para mantener la vinculación con su mundo relacional y afectivo, en definitiva todo aquello que entendemos como calidad de vida.

Las entidades que actualmente se encargan de asumir las tareas y funciones tutelares, tendrán que ir adaptando sus procesos a esta nueva filosofía, determinando no sólo los tipos de apoyo directos sino también los apoyos indirectos con el fin de conseguir la mayor y mejor calidad de las personas con necesidad de apoyos.

Además de garantizar que todas las personas puedan acceder a cualquier recurso, servicio, prestación, dispositivo, ayudas técnicas, a las que tenga derecho como cualquier ciudadano de acuerdo a sus necesidades, los profesionales de las entidades tutelares necesitarán realizar o recabar todos los informes sociales, médicos, jurídicos, etc.. que fundamente la tramitación de estos recursos o servicios.

Tramitar recursos y procurar que las personas con limitaciones judicialmente reconocidas encuentren menos dificultades para acceder a servicios y recursos no garantiza el bienestar y la salvaguarda de todos los derechos y condiciones de una vida digna. Es necesario que además del acceso a estos recursos, las personas puedan sentirse plenamente integradas y reconocidas en su medio, en su entorno social y de vida. Esta parcela más intangible, pero de importancia vital para las personas, es uno de los principales retos y nuevas formas de intervención que tendrán que asumir los profesionales que se encarguen de ejercer la figura de apoyo a las personas con capacidades modificadas judicialmente.

Es decir, necesariamente deberá haber una intervención más administrativa, de gestión de servicios, de control sobre los posibles servicios y recursos a los que pudiera tener derecho, eliminando las trabas administrativas y velando de manera rigurosa sobre estas cuestiones, pero además deberá haber 
un tipo de intervención, más cercano a las necesidades vitales de las personas, aspectos más intangibles y de características diferentes, tales como las referidas a su mundo de valores, relacional y de integración.

Ambas esferas de actuación son estrictamente necesarias. Sin garantía de derechos y sin tener cubiertas las necesidades a través de los recursos y servicios previstos por la sociedad para cualquier ciudadano o para determinados colectivos, es difícil o imposible poder plantearse una intervención más cercana y de calidad, centrada en los aspectos más emocionales, afectivos y relacionales.

Sobre estas áreas, la administrativa, la jurídica, la socioafectiva, es sobre las que se deberá rendir cuenta a la autoridad judicial, determinando mediante indicadores cuantitativos y cualitativos las actuaciones realizadas como resultado de lo que hemos denominado una Actuación Integral Centrada en la Persona (AICP).

Proteger a la persona con limitaciones y con la capacidad jurídica modificada, no deberá limitarse exclusivamente la intervención puntual, centrada exclusivamente en aquellas actuaciones que determine la sentencia judicial. El paso de la figura del tutor, como persona que sustituye y representa al incapacitado, a la figura del prestador de apoyos, requiere una mayor atención, ya que el apoyo implica el asesoramiento, la presencia, el consentimiento que se debe proporcionar a la persona para aquellas actuaciones puntuales como pueden ser las referidas a aspectos económicos, patrimoniales, a las transacciones económicas o negocios económicos, de manera que este apoyo, asesoramiento, deberá prestarse siempre que se produzcan actuaciones de naturaleza contractual y negocial.

El valor añadido que una entidad puede y debe prestar al proceso de apoyos a una persona con discapacidad está en poder contribuir a hacer una vida más «normalizada» a estas personas, lo cual pasa por trabajar otras áreas, tales como las referidas a la calidad de vida.

Las tareas de fortalecer las redes de apoyo, las redes personales, familiares y sociales, y fundamentalmente, la red de voluntariado, deben ser uno de los aspectos hegemónico, preferencial y estratégico, para que los vínculos personales, sociales, etc., no solo no se deterioren, sino que se fortalezcan. En este sentido, entendemos que la tarea del gestor de caso, debe ser el profesional que además de las actuaciones directas que establezca con la persona con discapacidad o necesitada de los apoyos, deberá velar porque las redes de proximidad, en las formas o modalidades que sean, permitan mejorar la vida y las condiciones de vida de las personas bajo su control. 
En este sentido, proponemos que las actuales entidades tutelares que se ocupan de asumir las figuras jurídicas de tutor, curador, administrador y defensor judicial, no solo pueden desempeñar esta protección y realizar las tareas de apoyo que plantea la Convención, sino que se encuentran en condiciones de ventaja, por su experiencia y por la forma de gestionar estas cuestiones. De igual manera que los padres delegan en los profesores las tareas de educación y formación que tienen con sus hijos menores, lo que no les excluye de su responsabilidad paterna, de forma similar, los familiares directos, las personas físicas que puedan prestar algunos de los apoyos más puntuales y esenciales a estas personas, no quedan excluidos, sino por el contrario fortalecidos, si se encuentran con entidades capaces de prestarles asesoramiento, de asumir tareas de tipo administrativo y de plantear procesos de actuación que permitan conectar a estas personas con redes diversas: económicas, productivas, educativas, sociales o relacionales.

Las entidades tutelares pueden desempeñar tareas que beneficien y mejoren la calidad de vida de las personas, ya que a la atención personal, centrada en la necesidad específica, aportan la conectividad social, relacional, impulsando el apoyo directo de parientes, familiares, amigos, vecinos y también de movimientos sociales y del voluntariado.

Enfoques y ejes que han de guiar un modelo de atención basado en los apoyos. Definición y propuestas

Planteamos en este apartado las características que debe tener un modelo vertebrador e integral para el apoyo de las personas con capacidades judicialmente modificadas como propuesta de acción futura desde el cambio de modelo que apuntan las tendencias actuales.

Para el desarrollo de estos epígrafes tenemos en cuenta aportaciones de diversos expertos, entre los que citamos a Viscarret, J.J. (2007), Casado, D. (2009), Sarabia Sánchez, A. (2007), Martínez, T. (2011), Martínez, T.; Díaz Viega, P.; Sancho, T.; y Rodríguez, P. (2014), entre otros.

El modelo de atención integral centrado en la persona

La CDPD, pretende acabar con un concepto de discapacidad o de persona con discapacidad que suponga exclusión, desigualdad e inferioridad. Por el contrario, define la discapacidad como un concepto que evoluciona y que resulta de la interacción entre las personas con deficiencias y las barreras debidas a la actitud y al entorno que evitan la participación plena y efectiva en la sociedad, 
en igualdad de condiciones con las demás, (Preámbulo, letra e). Bajo esta premisa plantea como principios (artículo 3):

a. El respeto de la dignidad inherente, la autonomía individual, incluida la libertad de tomar las propias decisiones, y la independencia de las personas.

b. La no discriminación.

c. La participación e inclusión plenas y efectivas en la sociedad.

d. El respeto por la diferencia y la aceptación de las personas con discapacidad como parte de la diversidad y la condición humanas.

e. La igualdad de oportunidades.

f. La accesibilidad.

g. La igualdad entre el hombre y la mujer.

h. El respeto a la evolución de las facultades de los niños y las niñas con discapacidad y de su derecho a preservar su identidad.

Partiendo de estos principios, cualquier modelo de intervención profesional para estos colectivos debe reunir dos características básicas: centrarse en la propia persona y plantear una actuación integral, es decir, debe tener en cuenta todas las áreas y necesidades de la persona.

Es amplia la literatura y las experiencias que definen el modelo de atención integral e innovador centrado en la persona (AICP), lo que significa buscar soluciones acordes a las necesidades y preferencias de las personas, teniendo en cuenta sus intereses, lo que no se puede hacer sin dar audiencia y participación a los receptores de los apoyos, si se les considera sujetos activos.

Como señalaba Rodríguez Poveda (2012), los deseos, características, derechos y preferencias de las personas deben ser el pilar básico para el desarrollo tecnológico y organizativo, como consecuencia de los nuevos retos y realidades sociales. Las innovaciones en bienes, servicios y procesos deben tener en cuenta que las personas que necesitan apoyos son sujetos activos en todos los aspectos de la vida, en los que no cabe ningún tipo de discriminación.

En la misma línea Rodríguez Rodríguez (2010) señala que la metodología de intervención necesariamente ha de estar centrada en la persona, de tal manera que los apoyos pasan por una atención integral centrada en la persona (AICP). El principio de cercanía, la no institucionalización, la permanencia en el entorno de vida familiar y cercano, son otros tantos principios indiscutibles, entre otras cosas porque hoy existen nuevas oportunidades a través del uso de las NT que pueden aplicarse para mejorar la atención sociosanitaria, la provisión de nuevos servicios o para prestar apoyos a las familias o a los movimientos de voluntariado. 
El modelo de intervención integral centrado en la persona, aplicado a los colectivos con la capacidad jurídica modificada, permite a los profesionales encargados de prestar los apoyos (gestores de caso) individualizar los mismos con el fin de garantizar la calidad de vida, entendida como la mejor expresión de los derechos, independientemente de las limitaciones o capacidades.

Tanto en la concepción actual sobre la tutela e incapacitación, como en la previsible futura reforma del Código Civil, la tarea de la persona encargada de proporcionar apoyos, necesita adecuar la intervención a las características de la persona a proteger. Ello significa reconstruir el mundo vital, subjetivo, ético, de principios y valores de la persona.

El conocimiento de qué es la discapacidad, la enfermedad mental o la vejez, de cómo es entendida y valorada en el contexto social, en el medio en el que vive, conocer la historia relacional, el entramado personal, el mundo afectivo o los procesos mentales que se derivan de la enfermedad invalidante, van a ser elementos fundamentales para los profesionales que se encarguen de mantener el contacto con la persona a la que han de prestar apoyos. Las fuentes de información serán tantas como sean necesarias para llegar a tener un mejor conocimiento de la persona: la propia persona si está en condiciones de poder dar esa información, familiares, personas de su red de relación, profesionales del área de la salud, de los servicios sociales, etc. El objetivo no puede ser otro que el de reconstruir esa historia personal para prestar un mejorar servicio.

La filosofía que debe inspirar la organización y el sistema de trabajo no ha de basarse en "hacer para o por otro», sino de hacer como el otro (la persona necesitada de apoyos) hubiera actuado de mantener intactas su capacidades. Sería como considerar los principios kantianos a la inversa: «haz por el otro lo que desearías que hicieran por ti».

\section{Modelo de calidad de vida}

Asimismo, además de la perspectiva que acabamos de plantear, la intervención integral centrada en la persona, requiere tener en cuenta que el objetivo es garantizar la calidad de vida de las personas necesitadas de apoyo. La «calidad de vida» es un constructo social que pone el acento en el valor de la persona, en sus necesidades y aspiraciones, teniendo en cuenta los valores y la forma de vida dominante en un determinado medio físico y social.

La calidad admite grados (puede ser desde «muy mala» a «muy buena») y también admite comparaciones. En este sentido, pretender alcanzar la «calidad de vida» en las personas con discapacidad y que tienen una fuerte dependencia tanto funcional como jurídica, es un objetivo que deberá medirse con 
parámetros tanto objetivos como subjetivos, pero en el marco de los derechos que plantea la CDPD. Por ello, cualquier negligencia en la atención, tanto personal, sanitaria, relacional como patrimonial, o abuso, supone un riesgo a la calidad de vida. Desde esta perspectiva tiene sentido la intervención personalizada o la intervención integral centrada en la persona.

Refiriéndose a las personas mayores en situaciones de dependencia, el Grupo de Expertos para el Consejo de Europa sobre la calidad de vida ${ }^{7}$, señala que bajo el concepto de calidad de vida se incluye: vida satisfactoria, bienestar subjetivo, bienestar psicológico, desarrollo personal y diversas representaciones de lo que constituyen una «buena vida». (Neugarten y col., 1961). Es decir, la calidad de vida va a depender de muchos factores personales: valores, cultura, experiencias, modo de vida, forma de posicionarse ante el dilema «ser o tener». Las condiciones sociales, el desarrollo social, la interacción de la persona con el contexto social, son elementos esenciales para definir este concepto de difícil medida, ya que las aspiraciones y realizaciones personales están muy mediatizadas por las oportunidades que ofrece la sociedad según su organización, servicios y desarrollo. Lo que no se conoce y lo que no se oferta, difícilmente puede ser objeto de deseo y conformar o satisfacer una necesidad no sentida.

Por eso entendemos la calidad de vida como el tipo de vida deseado por cada uno de los ciudadanos de una comunidad, definido dentro del marco de valores y recursos de esa comunidad. En nuestra sociedad la calidad de vida se interpreta desde el bienestar, los derechos y la autodeterminación. Así lo refiere Schalock al expresar que la calidad de vida «refleja las condiciones de vida deseadas por una persona en relación con ocho necesidades fundamentales que representan el núcleo de las dimensiones de la vida de cada uno: bienestar emocional, relaciones interpersonales, bienestar material, desarrollo personal, bienestar físico, autodeterminación, inclusión social y derechos» (1996: 108).

Es obvio que una persona no siempre podrá conseguir por sí misma todas estas esferas propuestas, sino que es preciso establecer un plan de apoyos para alcanzarlas o mantenerlas. Sin embargo, este concepto nos parece esencial para poder definir y orientar los programas de actuación individual, prestar y/o buscar los apoyos necesarios para que la persona con capacidades modificadas, o con muchas limitaciones, pueda disfrutar de la mejor calidad y protección.

7. O'Shea, E. (2003) La mejora de la calidad de vida de las personas mayores dependientes, Grupo de Expertos en la Mejora de la Calidad de Vida de las Personas Mayores Dependientes (CS-QV) Comité Europeo de Cohesión Social (CECS) Consejo de Europa, p. $10-11$ 
Poner el acento en la persona y en la calidad de vida es asumir principios y valores de las personas y considerar que no son destinatarias pasivas de un servicio, sino el elemento impulsor del mismo. Por ello un programa de apoyos que persiga la calidad de vida debe basarse en:

- El respeto, entendido como trato respetuoso, confidencialidad y privacidad.

- La comprensión, en el sentido de prestar el servicio respetando los principios, gustos e intereses, acercándose a la manera como la persona incapacitada lo haría, atendiendo a sus necesidades específicas y comprendiendo su situación personal.

- La equidad, o lo que es lo mismo, evitar discriminar a nadie por razones de edad, enfermedad, lugar de residencia, o por mantener o no relaciones con la familia.

Plantear como metodología una Atención Integral Centrada en la Personas (AICP) requiere que los profesionales de los servicios que prestan los apoyos, han de tener en cuenta y valorar el conocimiento de la realidad de la persona con discapacidad y usar su saber y su experiencia en conseguir la mejor calidad de vida, poniendo a su disposición los recursos y servicios necesarios para satisfacer sus necesidades. Medir la satisfacción de la persona necesitada de apoyos de manera fiable puede ser una tarea difícil; por ello se necesita construir algún sistema de indicadores que midan la calidad del servicio prestado.

Un modelo de gestión: la Gestión de caso

Para el desarrollo de esta perspectiva, tal como señala Rodríguez Rodríguez (2012), es necesario dar entrada a la figura del gestor de caso. Este modelo que nace en Estados Unidos, en la década de 1970, con el fin de corregir la respuesta fragmentada a las necesidades que plantea una misma persona. Es un modelo de intervención holístico, centrado en la persona, que tiene en cuenta el entorno e intenta potenciar la autonomía personal y la participación social y, sobre todo, facilita el acceso a recursos coordinados para responder a las necesidades de forma integral. Pretende colocar a la persona en el centro de la atención y de la prestación de servicios.

Desde esta concepción centrada en el valor de la persona, es lógico entender que para dar una respuesta global, coordinada e integral a todas las necesidades que pueda presentar, deberá existir un profesional de referencia que se encargue de conocer, demandar, orientar, gestionar y evaluar las diferentes intervenciones. Planificar e intervenir de manera racional es el eje 
fundamental del modelo, que desarrolla la filosofía que hemos planteado de intervención centrada en la persona.

La figura del gestor de caso es central en cualquier servicio o entidad que coordine las actuaciones y apoyos a personas que tengan las capacidades modificadas como consecuencia de su situación de discapacidad intelectual, enfermedad mental o envejecimiento, con el fin de organizar y coordinar todas las actuaciones, sin perder de vista la unidad e integralidad de la persona que recibe los apoyos, bien a través de los servicios o de los programas de actuación que se puedan diseñar en cualquiera de las esferas de la vida que se tengan que trabajar: educativa, laboral, jurídica, personal, familiar, social y relacional como en las áreas sanitarias, patrimoniales o económicas.

Si el profesional responsable de los apoyos tiene que dar respuesta a las necesidades de la persona con limitaciones y buscar su calidad de vida, es obvio que debe asumir la intervención de un modo coordinado con los diferentes servicios, entidades o profesionales que deban concurrir en la atención de la persona.

Cuando el encargado de prestar los apoyos es una persona jurídica, es decir una Asociación o una Fundación, es lógico pensar que es a estos profesionales a los que les corresponde asumir esa gestión, convirtiéndose el procedimiento o la metodología de gestión de caso en un elemento esencial de la entidad, que debe estar definido en el manual de buenas prácticas. Este método, a la vez que criterio de organización, deberá ser también esencial a la hora de establecer los ratios entre profesionales y personas a atender, ya que el gestor de casos o coordinador de procesos de actuación deberá concentrar su trabajo en aquellas personas que va a asumir de manera directa y responsable ante la entidad, para que ésta a su vez sea responsable ante la justicia. Si no están fijados los criterios o estándares de calidad, difícilmente se puede determinar el ratio de profesionales que pueden asumir el papel de responsables o gestores de caso.

Según Radol Raiff y Shore (1993) la gestión de caso es un servicio básico, que surge como componente fundamental del movimiento de desinstitucionalización, orientado hacia la normalización y que pretende la coordinación de los servicios destinados a aquellas personas que, viviendo en la comunidad, requieren intervenciones complejas de los sistemas de provisión comunitarios. La gestión de caso ha demostrado su validez al mostrar los beneficios que para las personas tiene el que se dé una respuesta integral y coordinada a sus necesidades y demandas; entre las ventajas se pueden citar: 
- Definir con claridad el ámbito de actuación.

- Hacer una valoración integral y detallada de la situación social de la persona, su estado físico, mental, psicológico, para identificar las necesidades y conocer los apoyos que precisa, mediante diversos instrumentos.

- Realizar un plan de intervención pautado teniendo en cuenta las necesidades y los recursos disponibles.

- Desarrollar o ejecutar el plan.

- Hacer el seguimiento de manera continua para detectar las necesidades y cambios que se puedan producir.

- Evaluar y replantear nuevas líneas de acción cuando sea necesario.

El profesional encargado de la gestión del caso representa el primer nivel de información, asesoramiento y orientación. Por tanto, es el encargado de realizar el oportuno seguimiento: detección de cambios en la evolución del itinerario personal, apoyar al resto de agentes o servicios que se vayan a prestar a la persona destinataria de los apoyos, entre los que destacan las personas de referencia emocional y cercana (Ej.- familiares, red de apoyo, voluntarios, etc.). Es también el encargado de establecer las conexiones formales con otros servicios y recursos diversos.

\section{Consideración final}

La filosofía que encierra la Convención de Naciones Unidas nos presenta un panorama general de un mundo que está cambiando, cambio que en el tema analizado se detecta en los siguientes procesos: De la independencia a la interdependencia, de los valores instrumentales a los valores finales, de la técnica a la ética, donde la vida humana tiene valor en sí misma y donde las normas han de centrarse en mejorar las condiciones de vida de las personas.

Hablar de apoyos es poner a la persona con necesidades especiales en el centro de la intervención, ya que los apoyos han de consistir en unas mejores prácticas profesionales y en disponer de recursos y estrategias que promuevan los intereses y las metas de las personas, con o sin discapacidad, que les posibiliten el acceso a recursos, información, bienes y relaciones propias de ambientes de trabajo y de convivencia, a la vez se incrementa la autonomía, la independencia e interdependencia, participación en su comunidad y satisfacción personal.

Prestar apoyos significa que las personas alcancen una vida plena y realizada, puedan elegir dónde quieren vivir, tengan los mismos derechos que cualquier otro ciudadano, estén satisfechos con su vida, en definitiva, tengan la misma consideración que el resto de personas. 
Aplicando los resultados de este trabajo a las políticas públicas, proponemos algunas alternativas y servicios que pueden mejorar la calidad de vida de las personas adultas incapacitadas judicialmente y el tipo de apoyos que se les puede prestar, de acuerdo a lo establecido en la Convención de Naciones Unidas. Destacamos en este sentido las siguientes aportaciones:

Propuesta de un modelo de gestión y organización basado en cooperación público privada para la gestión de servicios tutelares en Castilla y León, en el partenariado, la gobernanza y la sostenibilidad.

Diseño de un modelo de atención para las personas incapacitadas judicialmente (mayores, con discapacidad, en situación de dependencia o con enfermedad mental) basado en los apoyos, tal como lo entiende la Convención internacional de los Derechos de las Personas con Discapacidad.

Elaboración de un catálogo de servicios centrados en las políticas de apoyos que han de asumir y prestar las actuales entidades tutelares y/o entidades responsables de asumir las tareas que actualmente ejercen estas entidades si se produce un cambio legislativo en materia de tutela, de acuerdo con el mandato de la Convención de la ONU.

Diseño de un modelo de apoyos contando no solo con los profesionales sino también con la acción de un voluntariado bajo la coordinación de las fundaciones tutelares a través del gestor de caso, fortalecida esta actuación con la aplicación y uso de las Tecnologías, en el domicilio de las personas sometidas a control, apoyo y/o tutela y de los agentes de voluntariado que presten la colaboración con las entidades tutelares dentro de la filosofía de responsabilidad social ciudadana, la iniciativa social y la responsabilidad pública.

\section{Bibliografía}

BOE (2008). Convención sobre los derechos de las personas con discapacidad. BOE n. ${ }^{\circ} 96$ de 21 de abril de 2008

CABRA DE Luna, M.A. (2007) (Coord). Derechos humanos de las personas con discapacidad: La Convención Internacional de las Naciones Unidas. Madrid: Editorial Universitaria Ramón Areces.

CASADO, D. (Coord.) (2009). Gestión de caso (y métodos afines) en servicios sanitarios y sociales. Barcelona: Editorial Hacer.

Consejo de Europa, (1998). Recomendación n. ${ }^{\circ}$ R 99, du Comité des Ministres aux Etats Membres relative a la Dependence. Bruselas.

Fiscalía (2012). Memoria de la Fiscalía de Castilla y León (2011). http://www.fiscal.es 
GARCía Pons, A. (2008). Las personas con discapacidad en el ordenamiento jurídico español. La Convención Internacional de 13 de diciembre de 2006. Madrid: Editorial Universitaria Ramón Areces.

LEGERÉn Molina, A. (2012). La tutela del incapaz ejercida por la entidad pública. Estudio del artículo 239.3 del Código Civil. Madrid: Editorial Universitaria Ramón Areces.

MARTíneZ, T. (2011). La atención gerontológica centrada en la persona. Vitoria: Departamento Empleo y Asuntos Sociales. Gobierno Vasco.

Martínez, T.; Díaz Viega, P.; SAncho, T.; y RodríGueZ, P. (2014). Atención centrada en la persona. Cuadernos Prácticos. Vitoria: Fundación Matia. Departamento de Empleo y Políticas Sociales. Gobierno Vasco.

Naciones Unidas. CRPD/C/11/4 (2013). Observación general sobre el artículo 12: igual reconocimiento como persona ante la ley. Proyecto de observación general sobre el artículo 12, relativa al igual reconocimiento como persona ante la ley, fue preparado de conformidad con el artículo 47, párrafos 1 y 2 del Reglamento del Comité (CRPD/C/4/2) y el párrafo 54 de sus métodos de trabajo (CRPD/C/5/4).

Neugarten, B.L., Havighurst, R.J. y Tobin, S.S. (1961). Medición de una vida satisfactoria. Periódico de Gerontología, 16: 134-43.

O'SHEA, E. (2003) La mejora de la calidad de vida de las personas mayores dependientes, Grupo de Expertos en la Mejora de la Calidad de Vida de las Personas Mayores Dependientes (CS-QV) Comité Europeo de Cohesión Social (CECS) Consejo de Europa, p. 10-11.

Radol Raiff, N. y K. Shore, B. (1993). Advanced Case Management: New Strategies for the Nineties. Volumen 66 de SAGE Human Services Guides. SAGE Publications. Universidad de Michigan

Real Patronato sobre la Discapacidad (2013). Propuesta articulada de reforma del Código Civil y de la Ley de Enjuiciamiento Civil para su adecuación al artículo 12 de la Convención Internacional de los Derechos de las Personas con Discapacidad. Madrid. M. ${ }^{\circ}$ de Sanidad, Servicios Sociales e Igualdad, Fundación ONCE, Fundación Aequitas, Consejo General del Notariado España.

Recomendación Rec (2006) 5 del Comité de Ministros a los Estados miembros sobre el Plan de Acción del Consejo de Europa para la promoción de derechos y la plena participación de las personas con discapacidad en la sociedad: mejorar la calidad de vida de las personas con discapacidad en Europa 20062015, párrafo 2.2 .

Resolución 1642 (2009) de la Asamblea Parlamentaria: «Acceso a los derechos para las personas con discapacidad y su participación plena y activa en la sociedad», adoptada el 26 de enero de 2009 
RODRiguez POVEDA, R. (2012). La innovación centrada en la persona para el desarrollo tecnológico y organizativo. En http://www.fundacionpilares.org/docs/ encuentro_PPT_Poveda.pdf

RODRíguez RODRíguez, P. (2010). La atención integral centrada en la persona. Madrid, Informes Portal Mayores, n. ${ }^{\circ}$ 106. [Fecha de publicación: 04/11/2010]. <http://www.imsersomayores.csic.es/documentos/documentos/ pilar-atencion-01.pdf>

RODRIGUEZ RODRÍGUEZ, P. (2012) coord. Innovaciones en residencias para personas en situación de dependencia: Diseño arquitectónico y modelo de atención». Madrid: Fundación Caser para la Dependencia, Fundación Pilares para la Autonomía Personal.

RODRÍGUEZ, P. (2010). La atención integral centrada en la persona. Informes Portal Mayores, n. ${ }^{\circ}$ 106. (http://www.insersomayores.csic.es/documentos/documentos/pilar-atencion-01.pdf).

SARABIA SÁnCHEZ, A. (2007). La gestión de casos como nueva forma de abordaje de la atención a la dependencia funcional. Zerbitzuan. Revista de Servicios Sociales, n. ${ }^{\circ}$ 42: 7-17. Vitoria: Gobierno Vasco.

SCHAlOCK, L.R y VERDUGO, M.A. (2003). Calidad de Vida. Manual para profesionales de la salud, la educación y los servicios sociales. Madrid: Alianza Editorial.

VISCARreT, J.J. (2007). Modelos y métodos de intervención en Trabajo Social. Madrid: Alianza Editorial. 